\title{
Physiotherapy and Low Back PAin - PART II: OUTCOMES RESEARCH UTILISING THE Biopsychosocial Model: Biological OUTCOMES
}

\begin{abstract}
Low back pain $(L B P)$ is an acknowledged major health problem that is associated with high recurrence rates and increased chronic incapacity. It is one of the most common and costly conditions treated by physiotherapists and therefore the physiotherapy profession has a responsibility to provide evidence of effectiveness of interventions for $L B P$. The quality and rigour of published research on LBP has been found lacking and has predominately utilised a biomedical model of health that focuses on disease and system pathology rather than on illness. Outcomes

\section{BARDIN LD, B.Sc. (Physio.), Cert. OMT (SA), M.Sc. (Physio.) $)^{1}$}

1 University of Stellenbosch, South Africa. Current appointments: Private practitioner, Park Orchards Physiotherapy and Ringwood Physiotherapy and Spinal clinic, Melbourne, Australia. research has the potential to advance the quest for evidence of effective management of LBP. Patients with CLBP and disability face complex biopsychosocial problems, hence a multifactorial model of illness is particularly pertinent and is addressed by the outcomes research model. Outcome measures that are valid, reliable and responsive are necessary to determine effective interventions for LBP. Biological, psychological and social variables shape the experience and outcome of an episode of LBP and outcome measures reflecting all three aspects of the biopsychosocial model are important to the study of LBP. Outcome measures reflecting the biological component of the biopsychosocial model are discussed in part II: measures of pain and aspects of movement dysfunction.
\end{abstract}

KEY WORDS: LOW BACK PAIN, OUTCOME MEASURES, BIOPSYCHOSOCIAL MODEL, PAIN, MOVEMENT DYSFUNCTION, EFFECTIVE INTERVENTION, EVIDENCE-BASED PRACTICE.

\section{INTRODUCTION}

Low back pain (LBP) is acknowledged as a major health problem and LBP is the most common diagnosis for which patients are treated in outpatient physiotherapy settings (Jette and Davis 1991). As such, it should be of concern to the physiotherapy profession that the validity of current treatments for LBP is questioned (Waddell 1998; Watson 1999). High recurrence rates (Croft et al 1997) and increased chronic incapacity (Taimela et al 1997) associated with LBP, in particular chronic LBP (CLBP), are responsible for enormous costs to health budgets and require that physiotherapists respond positively to the challenge of analysing the quality and cost of care for acute and chronic LBP patients (Bardin 2002).

Providers of health care treating patients with LBP are increasingly being held accountable for standards of care and selection of treatment intervention. It is important to determine a valid approach to the management of LBP (Hazard et al 1994), as the complexity of LBP has been suggested to be equaled only by the variety of approaches to its prevention and treatment (Zanoli et al 2001). Diligent documentation of the outcome of care provided in clinical practice will enable clinical physiotherapists to measure change, an attainable goal for everyday clinicians, and has the potential to make a valuable contribution to the demand for evidence-based practice in the field of LBP management (Bardin 2002).

Outcomes research emphasises patients' assessments of pain, function, quality of life and satisfaction with the results of the intervention and is a feasible and affordable analysis of the outcome of healthcare (Bardin 2002). It would appear to be particularly suitable for measuring the impact of LBP, especially CLBP, on a patient's life. Outcome measures that reflect the biopsychosocial model are appropriate for measuring the multidimensional impact of LBP on patients' lives. Measures of pain and aspects of movement dysfunction represent the biological aspects of the biopsychosocial model and, together with psychosocial outcomes measures, appropriately capture the broad impact of LBP on patients' lives. Reduction in pain, improvement in function and prevention of disability are core aspects of physiotherapy management of LBP (Bardin 2002). It is therefore imperative that we seek affordable, clinically appropriate, responsive, valid and reliable measures of outcome to measure the effect of physiotherapy management of this costly and potentially disabling condition.

\section{THE BIOPSYCHOSOCIAL MODEL OF LOW BACK PAIN}

In the past health outcomes were defined rather narrowly and tended to focus pri-
CORRESPONDENCE TO:
Lynn Bardin
Park Orchards Physiotherapy
616 Park Road
Park Orchards
Victoria 3134
Australia
Tel: 9-6-13-98761964
Fax: 9-6-13-98790711
e-mail: lynnbardin@yahoo.co.uk 
marily on traditional physical outcomes that measured aspects of the biological component. Recently a much more comprehensive understanding of LBP has evolved. A biomedical model of health and dysfunction that views patients' disability and impairments as a reflection of their underlying tissue and system pathology (Jones et al 2002), is no longer thought to be good enough (Gatchel and Bell 2000a; Pinnington 2001). This has led to the use of a biopsychosocial model (incorporating the biological, psychological and social aspects of LBP and focusing on illness rather than disease) (Waddell et al 1992; Cherkin 1998). This is consistent with the International Classification of Functioning, Disability and Health (WHO, ICF 2001) of the World Health Organization (WHO): body function and body structures relating to the biological component, and activities, participation and environmental factors relating to the psychosocial impact on a person's functioning. Rose et al (1997) concluded that a multifactorial model of illness is particularly pertinent to the study of low back pain where behaviour, cognitive-behaviour, affective and socioeconomic variables have been recognised as shaping the experience and the outcome of an episode of low back pain (Engel 1959; Klenerman et al 1995; Pilowsky 1978; Turk and Rudy 1987; Hazard et al 1994).

Deyo and Diehl (1983) suggested that for LBP, impacts other than physical often need to be considered e.g. social and emotional states, and emphasised that some of these may be even more sensitive indicators of change than physical function. Hoffmann et al (1994) state that few physiologic tests of spine function, including laboratory and physical measurements, are clinically meaningful to patients, and that other outcomes are more relevant e.g. relief of symptoms (back and/or leg pain), improvement in functional ability, work status (including type of work), improvements in psychological measures, and use of health care resources and medication. Furthermore the Quebec Task Force suggested that generalisability is increased by selecting measures of health status that assess symptoms, functional ability and work status
(Quebec Task Force 1987). Qualitative studies have shown considerable functional and emotional impact on the lives of LBP patients (Borkon et al 1995; Skelton et al 1996; Miller et al 1999). Furthermore, many recent studies (Greenough and Fraser 1989; Bigos et al 1991; Coste et al 1994; Croft et al 1995; Mannion et al 1996; Papageorgiou et al 1997) draw attention to the effects of psychosocial factors on all aspects of LBP behaviour including the reporting of it and response to treatment (Adams et al 1999). These studies reinforce suggestions by Deyo and Diehl (1983) that, in many patients, objective physical findings are absent, and progress can only be assessed in terms of pain resolution and improved function; this appears to be consistent with the emphasis by Waddell et al (1992) that in CLBP there may no longer be any demonstrable structural impairment. Waddell and co-authors (Waddell et al 1992) were of the opinion that conventional physical outcome measures often assessed only a small portion of the spectrum of impacts caused by back pain, and suggested that the validity, reliability and sensitivity of these measures was uncertain. Recent research by Taimela and co-workers (Taimela et al 2000) suggests that psychological and psychosocial factors, patients' beliefs in control over pain (Härkapää et al 1991) and satisfaction with the overall treatment outcome have been more important predictors of outcome than objective physical and biomechanical findings. Taimela et al (Taimela et al 2000) concluded that selfexperienced beliefs regarding pain and function are more important indicators of successful low back rehabilitation than measurements of strength and mobility. Waddell found that correlations between pain, physical impairment and disability were low and that statistically these did not combine into a single score (Waddell 1987). Similarly Deyo found that physical parameters relating to the biological component (for example muscle strength and range of motion), were only weakly correlated with actual patient behaviour or symptoms (Deyo 1988). This would appear to be consistent with the fact that patients tend to define their problems in terms of dis- abilities and handicaps rather than impairments (Partridge 1984). The latter are regarded as relatively easy to measure, but would appear to be of questionable validity in terms of measuring outcome in relation to what patients perceive as their problems (Yekutiel 2002). Patients are experts on the subject of the condition that disables them, and if they want help, it is they who must tell us what they need (Yekutiel 2002). More recent research, however, has provided biological evidence, for example persistent muscle dysfunction as a factor in the chronicity/ recurrence of LBP (Hides et al 1994 and 1996; Hodges and Richardson 1996, 1997 and 1998). Research measuring outcome at the impairment level is likely to play a valuable role in advancing our understanding of biological factors influencing the aetiology of LBP and the risk factors for recurrence and for chronicity.

Gatchel and Mayer emphasised that the diversity of disability/illness expression (including its severity, duration, and consequences for an individual) is accounted for by the complex interrelationships among many factors: host, predisposition, physiology, psychology (e.g. genetic and prior learning experiences), and the sociocultural context that helped shape a person's perceptions and reactions to an adverse external or internal environment (Gatchel and Mayer 2000b). Main and Spanswick proposed an extended biopsychosocial model of disability (Main and Spanswick 2000). This model expands on the psychosocial influences inherent in the Mature Organism Model of health and disability (Gifford 1998); it illustrates the interactions between factors such as pain and deconditioning, fear and avoidance, depression, anger and frustration, iatrogenics, family, socio-economics and occupational factors (Jones et al 2002). In the quest for effectiveness of management for LBP patients, it is essential that outcome measures are developed and existing measures selected that reflect the impact of LBP on these multiple aspects of the illness experience. Furthermore recognition of the importance of patients' definition of their problems is likely to facilitate patient oriented therapy, in which patients themselves set the goals of their therapy 
and do not necessarily all aim for the same outcome (Yekutiel 2002).

It would appear that traditional outcome indicators, as utilised in the biomedical approach, are of little value in making decisions about the outcomes of care provided to those with chronic disabling illnesses of which CLBP is one of the most prevalent and most costly (Indahl et al 1995; Zusman 1997). Jette suggested that as the goals of health care have changed, so too must the indices used to evaluate the achievement of these goals (Jette 1993), and in a later study emphasised the importance of both impairment and disability outcomes (Jette 1995). Although active rehabilitation based on a biopsychosocial model is widely advocated in the literature (Pinnington 2001), Foster and colleagues (Foster et al 1999), in a survey throughout the United Kingdom, found that few physiotherapists utilised this approach. Cherkin suggested that if research is to provide substantial improvements for back pain, its focus must embrace an existing but nevertheless neglected paradigm, the biopsychosocial model (Cherkin 1998). Outcomes research of LBP is an aspect of clinical research that addresses the need for the application of the biopsychosocial model to the multidimensional study of the LBP patient (Bardin 2002).

\section{OUTCOME MEASURES FOR LOW BACK PAIN RESEARCH INCORPORATING THE BIOPSYCHO- SOCIAL MODEL}

Research of outcome measures is recognised as an important area of clinical research (Jull 1996; Stratford et al 2000; Huijbregts et al 2002), however it has been suggested that tools validated for research purposes are not always suitable for clinical purposes (Huijbregts et al 2002). Important information required by clinicians utilising outcome measures is: acceptability to patients, clinical feasibility, comparability of tools measuring similar constructs, discriminative and evaluative properties and normative data on various clinical populations to assist with interpretation: this information is suggested by Huijbregts et al to be important to enable clinicians to decide what are the most appropriate published measures for their patients and to inter- pret findings meaningfully (Huijbregts et al 2002). It has been suggested that, in most cases, gold standards do not exist and that the rigour of many studies investigating new measures and evaluating competing measures is questionable (Stratford et al 2000). Stratford and co-workers direct readers to 'how to' resources in their efforts to raise awareness of seven points that the authors believe will strengthen the conceptualisation, design and analysis of studies examining outcome/evaluative measures (Stratford et al 2000). Kirshner and Guyatt use the term evaluative measure (Kirshner and Guyatt 1985) to describe instruments used to assess change in patients over time and were the first to provide a definition for responsiveness defining it as the power of a test to detect clinically important difference (Kirschner and Guyatt 1985). Responsiveness, reliability and longitudinal construct validity are considered the three essential properties of an outcome measure (Stratford et al 2000), however it is beyond the scope of this paper to discuss these properties of outcome measures. It has been suggested that reliable, clinically responsive and relevant outcome measures are needed to assess change in three critical areas of patient management i.e. pain relief, physical capacity and disability (Liebenson and Yeomans 1997) and to determine the relevant effectiveness of different interventions for LBP. Recent research emphasises that the selection of outcome measures for the study of LBP should reflect the biopsychosocial model and the impact of LBP on multiple aspects of the illness experience (Stucki et al 1996; Deyo et al 1998; Bardin 1998, 2000b, 2000c and 2002).

\section{Pain}

Pain, an impairment relating to the biological and psychological component, is the common presenting symptom of most musculoskeletal conditions (Jahad and McQuay 1993) and is the most common presenting symptom in LBP patients (Bardin 1998; Zanoli et al 2001). The subjective intensity of pain is probably the aspect of pain most often measured in both clinical work and in treatment outcome research. There is a spectrum of syndromes within the descriptive symptom/category of LBP and it has been suggested that, within a great many variables influencing their condition, probably the only thing these patients have in common is back pain (Zanoli et al 2001).

The measurement of pain is considered important to evaluate the relative effectiveness of different therapies (Melzack and Katz 1994; Bardin 1998, 2000a, 2000b and 2002). Many different scales for the measurement of pain have been reported in the literature (Huskisson 1974; Joyce et al 1975; Scott and Huskisson 1976; Downie et al 1978; Kremer et al 1981; Seymour 1982; Sriwatanakul et al 1983; Jensen 1986; Murphy et al 1987; Duncan et al 1989; Bardin 2000b), however no gold standard exists for a measure to detect change in pain (Stratford et al 2000).

In a study comparing six methods of measuring clinical pain intensity it was found that each of the scales was a useful measure of subjective pain intensity and was suggested that any of these measures could be used to evaluate pain in a chronic pain population (Jensen et al 1986). However pain, particularly chronic pain is an elusive phenomenon to measure through objective means and as pain is a highly subjective experience, the use of multiple pain scales might reflect the pain state of a chronic pain patient more accurately (Bardin 1998). The scales reported by Jensen and co-workers included verbal rating scales, numerical pain rating scales (NPRS) and visual analogue scales (VAS) (Jensen et al 1986). Visual analogue scales provide simple and reliable measures of pain intensity (Huskisson 1974; Melzack and Katz 1994; Zanoli et al 2001). They have been widely used in clinical and research situations where a quick measure of pain is required and the numerical value given to the score makes for easy analysis and comparison. Other advantages of the VAS include ease and brevity of scoring, minimal intrusiveness, its conceptual simplicity (Melzack and Katz 1994), extra sensitivity (Huskisson 1974) and usefulness as a tool in describing spine patients (Zanoli et al 2001).

It has been suggested that patients find simple descriptive scales easier 
than VAS or NPRS (Bardin 1998), however earlier researchers stated that the VAS was the best method for measuring pain (Huskisson 1974). In a recent study (Tal-Akabi and Rushton 2000), however, the VAS and a modified pain relief scale (PRS) were used to compare the effectiveness of two interventions for the treatment of carpal tunnel syndrome. The results of the PRS were highly significant $(\mathrm{p}<0.01)$ and more sensitive than the VAS. The modified PRS (Tal-Akabi and Rushton 2000) appears to have high sensitivity. No examples of this outcome measure were found in studies of LBP, however it would appear to warrant investigation as a potential indicator of change in an acute or a chronic LBP population.

The McGill Pain Questionnaire (MPQ) (Melzack 1975) has been widely used as a clinical research tool. It evaluates the experience of pain in a multidimensional context using evaluative words that describe the total pain experience including sensory and affective qualities of pain (Melzack and Katz 1994). Melzack and Katz (1994) were of the opinion that the most important requirements of a measure are validity, reliability and clinical usefulness. Several authors suggest that the MPQ meets all of these requirements (Melzack 1983; Wilkie et al 1990) and provides a relatively quick method of measuring subjective pain experience (Melzack 1975). The internal structure of the MPQ was examined in studies by Turk and co-workers (Turk et al 1985), Lowe and colleagues (Low et al 1991), and Pearce and Morley (1989) confirming the three (sensory, affective and evaluative/cognitive) dimensions of pain. A short-form MPQ (SF-MPQ), more time efficient than the long-form MPQ (LF-MPQ) was developed and correlates very highly with the LF-MPQ and is able to detect clinical change (Melzack 1987; Harden et al 1991).

It has been suggested that describing pain solely in terms of intensity is like specifying the visual world only in terms of light flux without regard to pattern, colour, texture and the many other dimensions of visual experience (Melzack 1983). This view is supported by other researchers who contend that pain intensity, in itself, is not a reliable measure for dysfunction and for the outcome of management (Bardin 2000a, 2000b, 2000c, 2002; Duckworth 1999; Main and Watson 1999; Watson 1999; Ferguson 2000). Pain is always subjective, however recent research evaluated serum pseudocholinesterase levels in chronic spinal pain patients and found these levels to be objective, quantitative measurements of chronic spinal pain (Cameron et al 2000). Serum pseudocholinesterase levels were found to have a correlating trend with visual assessment scores and were significantly higher in chronic spinal pain patients than in normal control volunteers (Cameron et al 2000). Future research might provide additional objective outcomes of pain, but it remains important that other evaluations should be included which tap the dimension of the biopsychosocial framework for evaluating CLBP patients (Bardin 1997,1998, 2000b and 2002).

The presence and severity of pain is considered to be a narrow definition of health outcome (Ruta et al 1994; ICH 2001) and it is generally agreed that the ultimate goal of providing physiotherapy services to people with chronic disease is the improvement of functional status and ultimately the improvement of overall quality of life. Pain scales correlate poorly with physical function (Turk and Rudy 1987; Rainville et al 1992) and focus on impairment, therefore a shift to outcomes that reflect the goals of decreasing disability and improving quality of life have been recommended (Stucki et al 1996; Deyo et al 1998; Bardin 1998, 2000b and 2002). Pain, as perceived by the LBP patient, affects their ability to function and their quality of life (Bardin 1997, 1998, 2000) and, as measures of pain have been widely used in the study of LBP and have been reported to be a useful tool in describing spine patients (Zanoli et al 2001), it would appear useful to retain these in combination with measures of other aspects of the biopsychosocial model.

\section{Movement dysfunction}

It has been suggested that the clinical estimation of the amount of movement occurring in the lumbar spine is an important part of the investigation of patients with LBP (Rae et al 1984). The measurement of joint range of motion
(ROM) is often used to document the level of impairment and is a variable that is relatively easy to measure. It has been suggested to be more 'scientific' than the unmanageable sphere of patients' handicaps, their whims and peculiarities (Yekutiel 2002). External measurements of spinal ROM, which are easy to apply, are noninvasive and are commonly used (Ng et al 2001).

\section{Lumbar flexion}

It has been postulated that forward flexion is the most important measurement of lumbar spinal movement (Macrae and Wright 1969) and that the most important physical sign in the back is persistent severe restriction of lumbar flexion (Waddell 1998). The measurement of lumbar flexion is thought to offer clinically valuable information and limited flexion, together with other relevant clinical information, should alert the clinician to dysfunction or underlying disease (Waddell 1998). A traditional method of external measurement of lumbar flexion is the fingertip-to-floor test (Hoehler et al 1981). This test, however, includes the contribution of hip flexion (Rae et al 1984; Helliwell et al 1992) and therefore is only a gross measurement of lumbar flexion ( $\mathrm{Ng}$ et al 2001) and more a measure of general sagittal plane flexibility (Bardin 1998 and 2000b). The fingertipto-floor test is quick and user-friendly and Bardin (1998 and 2000b) used this method to assess progress in individual CLBP patients and in analysis of groups of CLBP patients undergoing group spinal rehabilitation. Bardin (1997, 1998, 2000a and 2000b) noted a 53\% improvement in flexibility 3 months after patients commenced rehabilitation, and noted a significant correlation between this method of measuring flexibility and functional disability measured on the Roland-Morris disability scale $(r=0,5$; $\mathrm{p}<0,01)$.

The modified Schober technique uses a more specific measure of movement in the lumbar spine, however it can measure only the lower lumbar levels (Macrae and Wright 1969) and has been suggested to be prone to errors (Reynolds 1975; Miller et al 1992). In a study by Adams and co-workers (Adams et al 1999) Schober value consistently failed 
to predict LBP of any description, but was related to the lumbar range of flexion $(\mathrm{p}<0.001)$ although accounting for less than $9 \%$ of it. The technique for measuring lumbar flexion recommended by the American Medical Association is the inclinometer technique (American Medical Association 1993), which records regional movement of the lumbar spine. This improves the accuracy of assessment of lumbar movement over a combined movement of the hip and spine (Burdett et al 1986). The inclinometer technique has been reported to be valid and reliable (American Medical Association 1993) and has been found to correlate well with measurements taken from a radiograph (Mayer et al 1984; Newton and Waddell 1991; Saur et al 1996).

\section{Lumbar extension}

Lumbar extension is the most commonly reported movement dysfunction in patients with lumbar spinal stenosis and therefore might be of particular relevance to measure in this sub-group of LBP patients. The inclinometer technique is a valid and reliable measure to record lumbar extension (American Medical Association 1993) however it has been suggested that lumbar extension may be difficult to measure (Ensink et al 1996; $\mathrm{Ng}$ et al 2001). A new measurement method using a pelvic restraint device in combination with an inclinometer showed good intra-tester reliability $(\mathrm{Ng}$ et al 2001), would appear to assist in measuring lumbar extension and showed good reliability ( $\mathrm{Ng}$ et al 2001).

\section{Lumbar lateral flexion}

Spinal ROM of lateral flexion has been reported to be a good indicator of the severity of low back pain (Michel et al 1997) and of disability (Waddell et al 1992). Fingertip-to-floor distance during lateral flexion is the common method of recording lateral flexion ROM, however, as with the fingertip-to-floor forward flexion measurement, this does not isolate flexibility specifically to the lumbar spine. Regional lumbar spine ROM in lateral flexion can be measured by using the validated inclinometer technique (American Medical Association 1993) or the method developed by $\mathrm{Ng}$ and co-workers ( $\mathrm{Ng}$ et al 2001).

\section{Lumbar rotation}

Trunk rotation is commonly measured by goniometric methods that include movement of the thoracic as well as the lumbar spine (Klein et al 1991). Loebl measured axial rotation of the lumbar spine (Loebl 1973) as did Twomey and Taylor (twomey and Taylor 1979), however, as pointed out by $\mathrm{Ng}$ and colleagues (Ng et al 2001), these investigations all placed the lumbar spine in flexion, which might be limited in a clinical situation. Lumbar axial rotation in standing has been measured using sophisticated equipment such as electromagnetic devices (Pearcy and Hindle 1989) and the computerised triaxial potentiometric system (Dvorak et al 1995). It would appear that the method developed by $\mathrm{Ng}$ et al ( $\mathrm{Ng}$ et al 2001) is preferable for clinical use.

In the recent study by $\mathrm{Ng}$ and coworkers ( $\mathrm{Ng}$ et al 2001) lumbar ROM in three planes was investigated using a pelvic restraint device and good reliability was shown for all the measures and compared well to corresponding values in various previous studies. The method of inclinometer technique with a pelvic restraint device appears to hold several advantages including support for the patients and better intra-tester reliability than in previous studies without the addition of the stabilisation device $(\mathrm{Ng}$ et al 2001).

Because movement dysfunction is a unique focus of physiotherapy (Van Dillen et al 1998) the majority of physiotherapy research focuses on improvements in impairments (such as range of motion, muscle strength and endurance). Some research focusing on impairment has made a unique contribution to advancing our understanding of recurrent/ chronic LBP (Hides et al 1994 and 1996; Hodges and Richardson 1996, 1997 and 1998). However, poor inter-observer agreement in rating spine motion and strength has been reported (Agre and Baxter 1987) and perhaps emphasises that outcomes more relevant to the patient and society are preferable: pain/symptoms, function, well-being, disability and satisfaction with care (Waddell et al 1992; Deyo 1983; Deyo et al 1998; Bardin 1997, 1998, 2000b, and 2002). It appears that recent research has improved the reliability of measures of lumbar spine ROM, however these measures do not emphasise the outcomes recommended for use in LBP research (Deyo et al 1998) or those outcomes that address patients' primary concerns i.e. pain and function (Turner et al 1992; Stucki et al 1996; Zanoli et al 2001).

Ferguson et al (2001) proposed that a better understanding about recovery from LBP can be gained if both activity and participation related outcome measures (for example, symptoms and activity of daily living (ADL) and impairment related outcome measures (for example, range of movement) (ICH 2001) are used to assess change in patients. These researchers monitored the natural course of acute LBP recovery prospectively using both traditional subjective outcome measures as well as objective quantitative kinematic measure and found that the latter quantifies a different aspect of impairment not evaluated by traditional subjective measures (Ferguson et al 2000). In this study ADL were evaluated using the Million Visual Analog scale (Million et al 1982) and results showed that the outcome measure of functional performance probability demonstrated the most distinct statistically significant improvement over the three month period (Ferguson 2000). Findings from this study supported Ferguson's suggestion that the use of several outcome measures would enhance understanding of recovery from acute LBP and could facilitate a reduction in the risk of recurrent injury.

It is generally agreed, however, that the ultimate goal of providing physiotherapy services to people with chronic disease is the improvement of functional status and ultimately the improvement of overall quality of life and for this reason a shift to outcomes which reflect these goals has been recommended (Bardin 1998, 2000c and 2002; Deyo et al 1998; Yekutiel 2002). Furthermore, collaboration of patients with physiotherapists to set treatment goals that reflect the patients' goals and objectives is likely to lead to improved patient motivation, outcomes and patient satisfaction.

\section{CONCLUSION}

Measures of pain and movement dysfunction are traditionally part of the 
biomedical model to investigate and study LBP; this model focuses on tissue and/or system pathology at the level of impairment, rather than on illness behaviour. Patients with CLBP and disability face multiple biopsychosocial problems and therefore a multifactorial model of illness is particularly pertinent to the documentation and study of the complexities of LBP and is consistent with the components and emphases of the ICF (WHO, ICF 2001). The biological outcomes of measures of pain and movement dysfunction can provide useful, easily quantifiable measures of change in patients with LBP problems. However, these outcome measures should be evaluated in conjunction with a battery of outcomes from the psychosocial aspects of the biopsychosocial model, at the level of activity and participation (WHO, ICF 2001). This has the potential to provide a measure of evidence of change that appropriately reflects the multidimensional impact of LBP in patients' lives. Studies utilising a spectrum of outcomes reflecting the biopsychosocial model are likely to capture unique aspects of understanding of LBP, foster a breadth of analysis of LBP extending far beyond the biomedical model and contribute to further scientific inquiry into the prevalent and problematic condition of LBP, in particular CLBP.

\section{ACKNOWLEDGEM ENT}

I should like to thank Dr. Nick Taylor, Department of Physiotherapy, La Trobe University, Melbourne, for his encouragement and comments on the manuscript.

\section{REFERENCES}

Adams MA, Mannion AF, Dolan P 1999 Personal risk factors for first-time low back pain. Spine 24:2497-2505

Agre JC, Baxter TL 1987 Musculoskeletal profile of male collegiate soccer players. Archives of Physical Medicine and Rehabilitation 68: 147 - 150

American Medical Association 1993 Guides to the evaluation of permanent impairment. 4th edition Chicago. American Medical Association

Bardin LD 1997 Outcome measurements in spinal rehabilitation - a case report. Proceedings of International congress of the South African Society of Physiotherapy, Cape Town, South Africa, April 1997

Bardin LD 1998 A study to evaluate the effectiveness of a total back care programme for group rehabilitation of selected patients with chronic low back pain. M.Sc. Thesis, University of Stellenbosch, South Africa

Bardin LD 2000a Outcomes research of a spinal rehabilitation programme for chronic/ recurrent low back pain. Proceedings of the South African Spine Society Congress, Cape Town, South Africa, June 2000

Bardin LD 2000b A Spinal Rehabilitation Programme for selected patients with recurrent/chronic low back pain: a one year prospective study. Proceedings of the 7 th Scientific Conference of the International Federation of Orthopaedic Manipulative Therapists, Perth, Australia, November 2000

Bardin LD 2000c Spinal rehabilitation of chronic low back pain using patient education and group exercise therapy. Course manual, pre-conference course, 7th Scientific Conference of the International federation of Orthopaedic Manipulative Therapists, Perth, Australia, November, 2000
Bardin LD 2002 Physiotherapy and Low Back Pain - Part I: Outcomes research in the quest for evidence. South African Journal of Physiotherapy 58:3-7

Bigos SJ, Battie MC, Spengler DM, Fisher LD, Fordyce WE, Hanson TM, Nachemson AL, Wortley MD 1991 A prospective study of work perceptions and psychological factors affecting the report of back injury. Spine 16:1 - 6

Borkon J, Reiss S, Hermani D, Biderman A 1995. Talking about the pain: A patient centred study of low back pain in primary care. Social Science and Medicine 40:977 - 988

Burdett RG; Brown KE; Fall MP 1986 Reliability and validity of four instruments for measuring lumbar spine and pelvic positions. Physical Therapy 66:677 - 684

Cameron BM, Allen RC, Merril C 2000 A prospective study of serum pseudocholinesterase levels in patients with chronic spinal pain. Spine 25:1917 - 1924

Cherkin DC 1998. Primary Care Research on Low Back Pain. Spine 23:1997-2002

Coste J, Delecoeuillerie G, Cohen de Lara A, Le Parc JM, Paologgi JB 1994 Clinical course and prognostic factors in acute low back pain: An inception cohert study in primary care practice. British Medical Journal 308:577 -580

Croft PR, Papageorgiou AC, Ferry S, Thomas E, Jayson MIV, Silman AJ 1995 Psychological distress and low back pain: evidence from a prospective study in the general population. Spine 20:2731 - 2737

Croft PR, Papageorgiou AC, McNally R 1997 Low back pain: Healthcare needs Assessment. Radcliffe Medical Press, Oxford

Deyo RA 1983 Conservative therapy for low back pain: distinguishing useful from useless therapy. Journal of the American Medical Association 250:1057 - 1062
Deyo RA 1988 Measuring the functional status of patients with low back pain. Archives of Physical Medicine and rehabilitation 69:1044 - 1053

Deyo RA, Diehl AK 1983 Measuring physical and psychosocial function in patients with low back pain. Spine 8:635 - 642

Deyo RA, Battie M, Beurskens AJHM, Bombardier C, Croft P, Koes B, Malmivaara A, Roland M, Von Korff M, Waddell G 1998 Outcome Measures for Low Back Pain Research: a proposal for standardised use. Spine 23:2003-2013

Downie WW, Leatham PA, Rhind VM, Wright V, Branco JA, Anderson JA 1978 Studies with pain rating scales. Annals of the Rheumatic Diseases 37:378 - 381

Duncan GH, Bushnell MC, Lavigne GJ 1989 Comparison of verbal and visual scales for measuring the intensity and unpleasantness of experimental pain. Pain 37:295-303

Duckworth M 1999 Outcome measurement. Selection and typology. Physiotherapy 85: $21-27$

Dvorak J, Vajda EG, Grob D, Panjabi MM 1995 Normal motion of the lumbar spine as related to age and gender. European Spine Journal 4:18 - 23

Engel GL 1959 The biopsychosocial model and medical education. New England Journal of Medicine 196:129 - 136

Ensink FB, Saur PM, Frese K, Seeger D, Hildebrand J 1996 Lumbar range of motion: influence of time of day and individual factors on measurements. Spine 21:1339- 1343

Ferguson SA, Marras WS, Gupta P 2000 Longitudinal quantitative measures of the natural course of low back pain recovery. Spine 25:1950 - 1956 
Foster N, Thompson K, Baxter D, Allen J 1999 Management of non-specific low back pain by physiotherapists in Britain and Ireland. Spine: 1332-42

Gatchel RJ, Bell G 2000a Editorial: The biopsychosocial approach to spine care and Research. Spine 25:2572

Gatchel RJ, Mayer TG 2000b Occupational musculoskeletal disorders: Introduction and overview of the problem. In: Mayer TG, Gatchel RJ, Polatin PB, eds. Musculoskeletal disorders: Function, outcomes and evidence. Lippincott Williams and Wilkins, Philadelphia.

Gifford LS 1998 The Mature Organism Model. In: Gifford LS (ed) Topical issues in Pain I. Whiplash - science and management. Fear avoidance beliefs and behaviour. CNS Press, Falmouth ch. 2 p. 45

Greenough CG, Fraser RD 1989 The effects of compensation on recovery from low back injury. Spine 14:947-955

Harden RN, Carter TD, Gilman CS, Gross AJ, Peters JR 1991 Ketorolac in acute headache management . Headache 31:463-464

Härkäpää K, Jarvikoski A, Mellin G, Murri H, Luoma J 1991 Health locus of control beliefs and psychological distress as predictors for treatment outcome in low back pain patients: results of a 3-month follow-up of a controlled intervention study. Pain 46:35-41

Hazard RG, Haugh LD, Green PA, Jones P 1994 Chronic low back pain: the relationship between patient satisfaction and pain, impairment and disability outcomes. Spine 19: 881-887

Helliwell P, Moll J, Wright V 1992 Measurement of spinal movement and function. In: Jayson MIV, ed. The lumbar spine and back pain, 4th edition. Churchill Livingstone, Edinburgh p.173-205

Hides JA, Stokes MJ, Saide M, Jull GA, Cooper DH 1994 Evidence of lumbar multifidus muscle wasting ipsilateral to symptoms in patients with acute/subacute low back pain. Spine 19:165-172

Hides JA, Richardson CA, Jull GA 1996 Multifidus muscle recovery is not automatic after resolution of acute first episode low back pain. Spine 21:2763-2769

Hodges PW, Richardson CA 1996 Inefficient muscular stabilisation of the lumbar spine associated with low back pain: a motor control evaluation of transversus abdominis. Spine 21:2640-2650

Hodges PW, Richardson CA 1997 Contraction of the abdominal muscles associated with movement of the lower limb. Physical Therapy $77: 132-142$

Hodges PW, Richardson CA 1998 Delayed postural contraction of transversus abdominis in low back pain associated with movement of the lower limb. Journal of Spinal Disorders $11: 46-56$

Hoehler KK, Tobis JS, Buerger AA 1981 Spinal manipulation for low back pain. Journal of American Medical Association 245:1835-1838

Hoffmann RM, Turner JA, Cherkin DC, Deyo RA, Herron LD 1994 Therapeutic trials for low back pain. Spine 19:2068S-2075S

Huskisson EC 1974 Measurement of pain. Lancet 2:1127-1131

Huijbregts MPJ, Myers AM, Kay TM, Gavin TS 2002 Systematic outcome measurement in clinical practice: Challenges experienced by physiotherapists. Physiotherapy Canada winter: 25-36

Indahl A, Velund L, Reikeraas O 1995 Good prognosis for low back pain when left untampered. Spine 20:473-477

Jahad AR, McQuay HJ 1993 The measurement of pain. In: Pynsent P, Fairbank J, Carr A eds. Outcome Measures on Orthopaedics. Butterworth-Heinemann, Oxford p.16-29

Jensen MP, Karoly P, Braver S 1986 The measurement of clinical pain intensity: a comparison of six methods. Pain 27:117 - 126

Jette AM 1993 Using health related quality of life measures in physical therapy outcomes research. Physical Therapy 73:528 - 536

Jette AM 1995 Outcomes research: shifting the dominant research paradigm in physical therapy. Physical Therapy 75:965 - 970

Jette AM, Davis KD 1991 A comparison of hospital-based and private outpatient physical therapy practices. Physical Therapy 74:366-375

Jones M, Edwards I, Gifford L 2002 Conceptual models for implementing biopsychosocial theory in practice. Manual Therapy 7:2-9

Joyce CRB, Zutshi DW, Hrubes V, Mason RM 1975 Comparison of fixed interval and visual analogue scales for rating chronic pain. European Journal of Clinical Pharmacology $8: 415-420$

Jull GA 1996 Challenges for clinicians in outcome research. Proceedings of National Physiotherapy Congress, Brisbane, Australia
Klein AB, Snyder-Mackler L, Roy SH, DeLuca CJ 1991 Comparison of spinal mobility and isometric trunk extensor forces with electro-myographic spectral analysis in identifying low back pain. Physical Therapy $71: 445-454$

Klenerman L, Slade PD, Stanley IM 1995 The prediction of chronicity in patients with an acute attack of low back pain in a general practice setting. Spine 20:478 - 484

Kremer E, Atkinson JH, Ignelzi RJ 1981 Measurement of pain: patient preference does not confound pain measurement. Pain 10:241-248

Liebenson C, Yeomans S 1997 Outcomes assessment in musculoskeletal medicine. Manual Therapy 2:67 - 74

Loebl WY 1973 Regional rotation of the spine. Rheumatology and rehabilitation $12: 223$

Lowe NK, Walker SN, McCallum RC 1991 Confirming the theoretical structure of the McGill Pain Questionnaire in acute clinical pain. Pain 46:53-60

MaCrae JF, Wright V 1969 Measurement of back movements. Annals of Rheumatic Diseases 28:584 - 589

Main CJ, Watson PJ 1999 Physiological aspects of pain. Manual Therapy 4:203-215

Main CJ, Spanswick CC 2000 Models of Pain. In: Main CJ, Spanswick (eds) Pain Management: An interdisciplinary approach. Churchill Livingstone, Edinburgh Ch 1 p. 3

Mannion AF, Dolan P, Adams MA 1996 Psychological questionnaires: Do "abnormal" scores precede or follow first-time low back pain. Spine 21:2603-2611

Mayer TG, Tencer AF, Kristoferson S, Mooney V 1984 Use of noninvasive techniques for quantification of spinal rangeof-motion in normal subjects and chronic lowback dysfunction patients. Spine 9:588-595

Melzack R 1975 The McGill Pain Questionnaire: Major properties and scoring methods. Pain 277-299

Melzack R 1983 Pain measurement and assessment. Raven Press, New York.

Melzack R 1987 the short-form McGill Pain Questionnaire. Pain 30:191-197

Melzack R, Katz J 1994 'Pain measurement in persons in pain' in: Textbook of Pain, Third edition, eds. Wall PD and Melzack R. Churchill Livingstone, London 
Michel A, Kohlmann T, Raspe H 1997 The association between clinical findings on physical examination and self-reported severity in back pain: results of a population-based study. Spine 22:296-304

Miller SA, Mayer T, Cox R, Gatchel RJ 1992 Reliability problems associated with the modified Schober technique for true lumbar flexion measurement. Spine 17:345-348

Miller J, Pinnington M, Stanley I 1999 The early stages of low back pain: A pilot study of patient diaries as a source of data. Family Practice 16:395-401

Million R, Hall W, Nilsen K, Baker R, Jayson M 1982 Assessment of the progress of the back pain patient. Spine 7:204-212

Murphy DF, McDonald A, Power C, Unwin A, MacSullivan R 1987 Measurement of pain: a comparison of the visual analogue with a non-visual analogue scale. Clinical journal of pain 3:197-199

Newton M, Waddell G 1991 Reliability and validity of clinical measurement of the lumbar spine in patients with chronic low back pain. Physiotherapy 77:796-800

Ng J, Kippers V, Richardson CA, Parnianpour M 2001 Range of motion and lordosis of the lumbar spine. Spine 26:53 - 60

Papageorgiou AC, MacFarlane GJ, Thomas E, Croft PR, Jayson MI, Silman AJ 1997 Psychosocial factors in the workplace - do they predict new episodes of low back pain? Evidence from the South Manchester Back Pain Study. Spine 22:1137-1142

Partridge CJ 1984 Recovery from conditions involving physical disability 70:233-235

Pearce J, Morley S 1989 An experimental investigation of the construct validity of the McGill Pain Questionnaire. Pain 39:115 - 121

Pearcy MJ, Hindle RJ 1989 New method for the noninvasive three-dimensional measure of human back movement. Clinical biomechanics $4: 73-79$

Pilowsky I 1978 A general classification of abnormal illness behaviour. British Journal of Medical Psychology 51:131 - 137

Pinnington MA 2001 Why are we finding it so hard to change our approach to lowback pain? Physiotherapy 87:58 - 59

Quebec Task Force 1987 Quebec Task Force on spinal disorders: scientific approach to the assessment and management of activity related spinal disorders. Spine 12 :S16-21

Rae PS, Waddell G, Venner RM 1984 A simple technique for measuring lumbar spinal flexion. Journal of the Royal College of Surgeons of Edinburgh 29:281 - 284

Rainville J, Ahern DK, Phalen L, Childs LA, Sutherland R. 1992 The association of pain with physical activities in chronic low back pain. Spine 17:1060-1064

Reynolds PMG 1975 Measurement of spinal mobility: a comparison of three methods. Rheumatology and rehabilitation 14:180-185

Rose MJ, Reilly JP, Pennie B, Bowen-Jones K, Stanley IM, Slade PD 1997 Chronic low back pain rehabilitation programs. Spine 22: 2246-2253

Ruta DA, Garratt AM, Wardlaw D, Russell IT 1994 Developing a valid and reliable measure of health outcome for patients with low back pain. Spine 19:1887-1896

Saur PM, Ensink FB, Frese K, Seeger D, Hildebrandt J 1996 Lumbar range of motion: reliability and validity of the inclinometer technique in the clinical measurement of trunk flexibility. Spine 21:1332-8

Scott J, Huskisson EC 1976 Graphic representation of pain. Pain 2:175-184

Seymour RA 1982 The use of pain scales in assessing the efficacy of analgesics in postoperative dental pain. European journal of clinical pharmacology 23:441-444

Skelton A, Murphy EA, Murphy RJL, O’Dowd TC 1996 Patients' views of low back pain and its management in general practice. British Journal of General Practice 46:153 - 156

Sriwatanakul K, Kelvie W, Lasagna L, Calimlim JF, Weis OF, Mehta G 1983 Studies with different types of visual analogue scales for measurement of pain. Clinical pharmacology and therapeutics 34:234-239

Stratford PW, Spandoni G, Kennedy D, Westaway MD, Alcack GK 2000 Seven points to consider when investigating a measure's ability to detect change. Physiotherapy Canada 54:16-24

Stucki G, Daltroy L, Liang M, Lipson S, Fossel A, Katz JN 1996 Measurement properties of a self-administered outcome measure in lumbar spinal stenosis. Spine 21:796 - 803

Taimela S, Kujala UM, Salminem JJ, Viljanen T 1997 The prevalence of low back pain among children and adolescents: A nationwide, cohortbased questionnaire survey in Finland. Spine 22:1132-1136

Taimela S, Diederich C, Hubsch M, Heinricy M 2000 The role of physical exercise and inactivity in pain recurrence and absenteeism from work after active outpatient rehabilitation for recurrent or chronic low back pain. Spine 25:1809-1816
Tal-Akabi A, Rushton A 2000 An investigation to compare effectiveness of carpal bone mobilisation and neurodynamic mobilisation as methods of treatment for carpal tunnel syndrome. Manual Therapy 5:214-222

Turk DC, Rudy TE, Salovey P 1985 The McGill Pain Questionnaire reconsidered: confirming the factor structure and examining appropriate uses. Pain 21:385 - 397

Turk DC, Rudy TE 1987 Toward a comprehensive assessment of chronic pain patients. Behaviour research and therapy 25:237 - 249

Turner DC, Ersek M, Herron L, Deyo R 1992 Surgery for lumbar spinal stenosis: attempted meta-analysis of the literature. Spine 17:1-8

Twomey L, Taylor J 1979 A description of two new instruments for measuring the ranges of sagittal and horizontal plane motions in the lumbar region. Australian Journal of Physiotherapy 25:201-203

Van Dillen L, Sahrmann SA, Norton BJ, Caldwell CA, Flemming DA, McDonnell MK, Woolsey NB 1998 Reliability of physical examination items used for classification of patients with low back pain. Physical Therapy 78:980-988

Waddell G 1987 Clinical assessment of lumbar impairment. Clinical Orthopaedics 221:110 120

Waddell G, Somerville D, Henderson I, Newton M 1992 Objective clinical evaluation of physical impairment in chronic low back pain. Spine 17:617-628

Waddell G 1998 The Back Pain Revolution, Churchill Livingstone, London.

Watson PJ 1999 Psychosocial Assessment. Physiotherapy 85: 530-535

Wilkie DJ, Savedra MC, Holzemer WL, Tesler MD, Paul SM 1990 Use of the McGill Pain Questionnaire to measure pain: a meta-analysis. Nursing Research 39:36-41

WHO, ICF 2001 International Classification of Functioning, Disability and Health, Geneva.

Yekutiel M 2002 Editorial - clinical trials of patient oriented therapy. Physiotherapy Research International 7:iii-iv

Zanoli G, Stromqvist B, Jonsson BO 2001 Visual analogue scales for interpretation of back and leg pain intensity in patients operated for degenerative lumbar spine disorders. Spine 26:2375-2380

Zusman M 1997 Instigators of activity intolerance. Manual Therapy 2:75-86 